\title{
CONGRESSIONAL BRIEFINGS
}

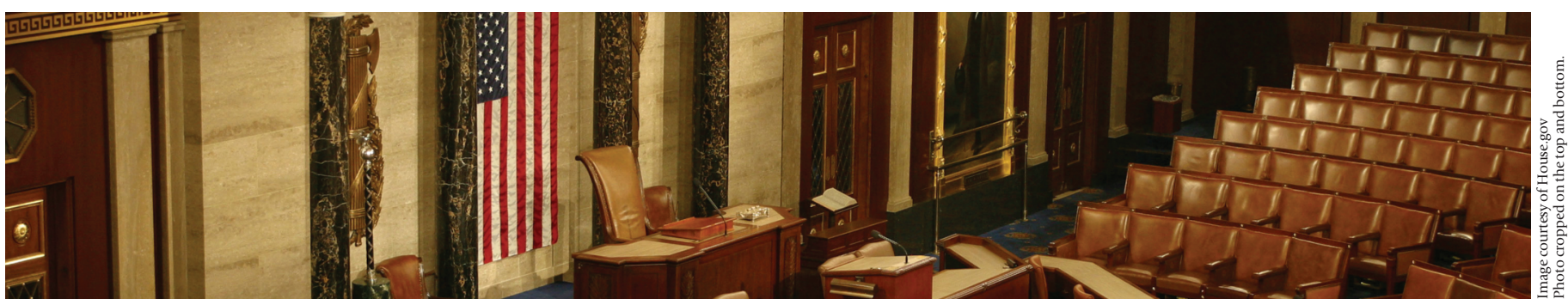

\section{Math Societies to Lawmakers: Help Us Make the Master Key}

\section{Sophia D. Merow}

\section{Biannual Briefings}

The American Mathematical Society (AMS) Office of Government Relations (https://www.ams.org/government /government) - jointly with the Mathematical Sciences Research Institute (MSRI) - sponsors two congressional briefings per calendar year. ${ }^{1}$ These briefings provide an opportunity for the mathematics community to impart information to policymakers and, in particular, to tell compelling stories of how federal investment in basic research in mathematics pays off for the American taxpayer.

At a lunch briefing in the Dirksen Senate Office Building on December 4, 2018, Rodolfo H. Torres gave the Hill staffers in attendance what former US Representative Bart Gordon (D-TN) called "ammunition" for their science advocacy. In his half hour at the lectern, the University of Kansas mathematician (and AMS Fellow) made the case for federal funding of basic research by showing how investigation of foundational questions can launch lines of inquiry that produce, sometimes decades later, societally beneficial applications galore.

"This is the way, many times, research takes place," Torres explained. "We move from fundamental research in maybe math, physics, or biology to applied research in which we

Sophia D. Merow is Special Projects Editor and Notices assistant. Her email address is merow. notices@gmai 1 .com.

${ }^{1}$ For coverage of the first congressional briefing of 2018, see the January 2019 Notices https: //www.ams.org/journals /notices/201901/rnoti-p102.pdf.

For permission to reprint this article, please contact: reprint -permission@ams.org.

DOI: https://dx.doi.org/10.1090/noti 1849 want to apply these tools to solve specific problems, and eventually we get-sometimes-to translational research. We find cures for diseases and solve problems that affect our society and the way in which we live."

Titled "From the Color of Birds to Nanomaterials and New Technologies," Torres's talk juxtaposed what he acknowledged to be an unlikely trio of topics, "things you won't normally think to find in the same sentence." Before Torres discussed the blue hue of birds, however, he used analogies to give his audience a feel for Fourier analysis.

Fourier analysis decomposes a signal into a combination of oscillating waves of different frequencies and amplitudes, he said, much as a prism separates a beam of light into a spectrum of colors of different wavelengths. Representing a signal using its Fourier coefficients is like writing a recipe for a cake when the ingredients-here the waves of different frequencies-are always the same. The amounts-the amplitudes-suffice to encode the information. Similarly, Torres explained, a two-dimensional image can be represented as a superposition of planar waves. 
Torres briefly displayed a slide bearing (along with two recent Notices covers) a list of the "arsenal of tools" that deploy Fourier analysis for signal analysis and image processing: wavelets, curvelets, diffusion maps, compressed sensing... "By treating signals and images as mathematical objects, they can be quantitatively and algorithmically manipulated to extract, enhance, filter, and compress the information they represent," the slide read.

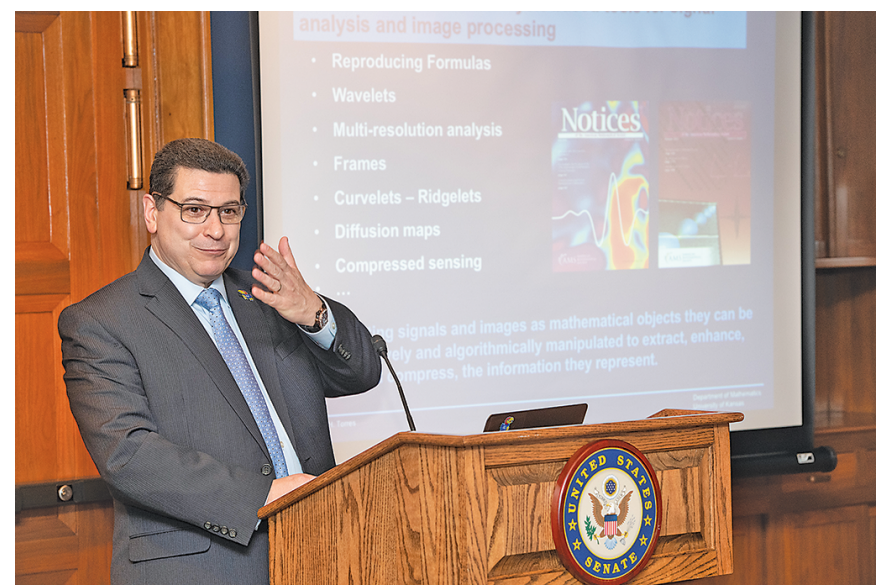

RodolfoTorres mentions the arsenal of tools for signal analysis and image processing that are based on Fourier analysis.

Wavelets afforded Torres the opportunity to both discuss return on federal investment in mathematics and provide a first sampling of useful applications. A. P. Calderón's 1964 paper "Intermediate spaces and interpolation, the complex method" includes the following acknowledgement: "This work was partly supported by N.S.F. grant GP.-574."

"So this paper of Calderón, which is the birth of wavelets [within mathematics], was funded by the National Science Foundation in 1964," Torres said. "I would be very curious to know how much was awarded to Calderón."

From Calderón's likely modest seed grant has grown a field of research with ramifications for everything from national security to agriculture. While the FBI can't match crime-scene fingerprints to those of known criminals quite as quickly as detectives do in television procedurals, wavelet-based compression of fingerprint images does speed up the process. Statistical analysis using wavelets of computed tomography (CT) images enables more accurate determination of cancer prognosis. Applying Fourier analysis to satellite imagery gives soybean producers in the American heartland projected crop yields for their competitors in Brazil.

But back to the titular birds. It turns out that the blue facial skin sported by birds such as the asities of Madagascar derives its color not from a pigment but from the structure of the tissue itself. The skin is composed of long, thin collagen fibers. Look at it with an electron microscope and you see something like the cross section of a bundle of angel hair spaghetti. Torres and his biologist colleagues saw a certain order in these cross sections, and they adapted the two-dimensional Fourier transform to analyze the periodicity and optical properties of the tissue. They demonstrated that the nanostructure of the collagen arrays accounts for that brilliant blue.

"Only certain wavelengths that resonate with the physical distance present in the material get scattered," Torres explained, "and those are the ones we see."

Such structural color exists not just in birds but also in mammals (a mandrill's nose, for instance), butterflies, and dragonflies. And photonic structures, structures that selectively interfere with light, don't possess only optical properties. They can also render tissues antibacterial or self-cleaning or superhydrophobic (extremely difficult to wet). Study of tissues with desirable properties such as these has "really led to what I would call the bioinspired nanomaterial revolution," said Torres.

Research in the field of evolutionary photonics promises applications in renewable energy, nanomedicine, and advanced material engineering. Torres encouraged audience members to visit the website of the NSF-funded National Nanotechnology Coordinated Infrastructure (https:// www. nnci . net) to learn how nanostructures might enable more efficient light harvesting or advance energy storage. As an example of a medical application of nanofabrication, he highlighted a flexible membrane hundreds of times thinner than aluminum foil that alleviates glaucoma by distributing pressure and facilitating absorption of fluid buildup.

Torres closed his talk by reiterating the role of mathematics in science and technology and underscoring the potential of basic mathematics to unlock future advances. "When we start talking about order and symmetry and geometry, this is the field of mathematics," Torres said. Mathematicians can quantify this order (or lack thereof), thereby explaining

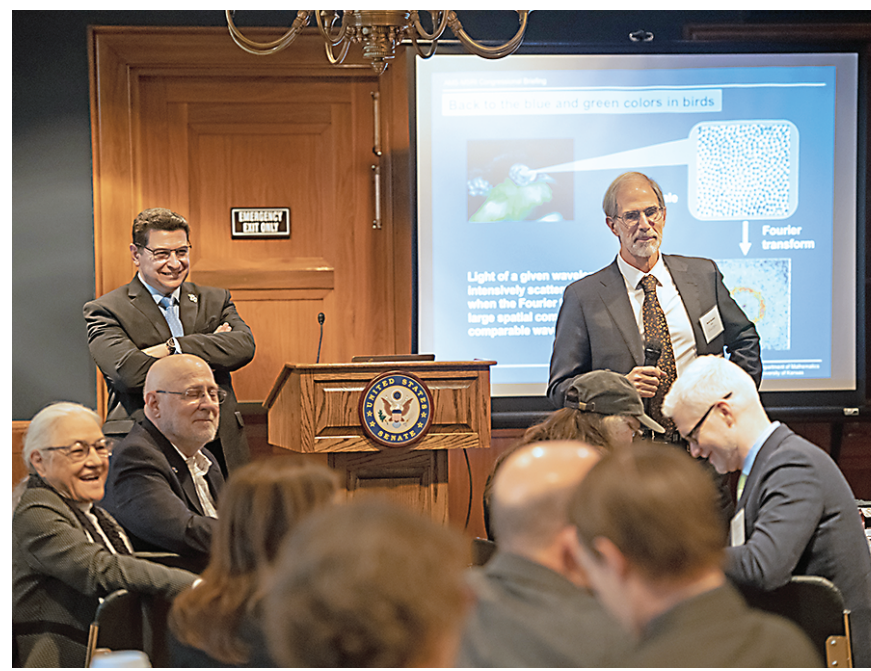

MSRI Director David Eisenbud (standing right) solicited from audience members their reasons for attending the briefing. 
physical phenomena found in nature. These newly understood natural phenomena then serve as inspiration for cutting-edge human-developed technologies.

Torres suggested thinking of applied research as building a key to a particular door we need to open. Fundamental research, in contrast, is like creating a master key, one that will open many different doors. "In fact, it's going to be opening doors that you still don't know that you need to open," he said. "But you will have it ready when the need arises."

Of course the purpose of congressional briefings such as the one on December 4 is to publicize among policymakers and keepers of the federal purse-strings instances of sometimes long-unused master keys of mathematics opening societally fruitful doors. It's a service that Joel Creswell from the office of Congressman Daniel Lipinski (D-IL) appreciates as he supports Lipinski's work on the Committee of Science, Space, and Technology.

"These aren't stories that you can come up with from looking at the research literature," he said in response to MSRI Director David Eisenbud's post-presentation question about what prompted audience members to attend. "You really need experts in the field to be able to say, 'Here's a discovery that traces back to this basic research.'"

\section{What You Can Do}

You, too, can help get the word out about the importance of funding basic research:

- Write a letter to your senator or representative.

- Write an op-ed for a local publication.

- Organize a talk at your institution about the unexpected utility of basic math. Invite your representative and work with your school's government relations office.

- See the AMS Office of Government Relations' "Tools to take action" page https://www. ams . org /government/dc-prepare to get started.

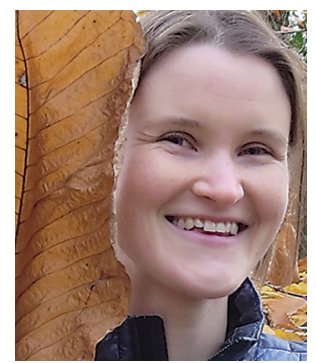

Sophia D. Merow

Credits

Author photo is by Craig Merow.

All other photos are by Scavone Photography.

\section{MATHPROGRAMS.ORG} ...

\section{With MathPrograms.Org you can:}

- Receive, read, rate, and respond to electronic applications for your mathematical sciences programs, such as undergraduate summer research programs and travel grant competitions.

- Customize your settings and control the application form; also set secure access for the admissions committee.

- Enter program announcements for public display.

- Download data to personal computers for use in word processing and spreadsheets or as a full permanent storage file.

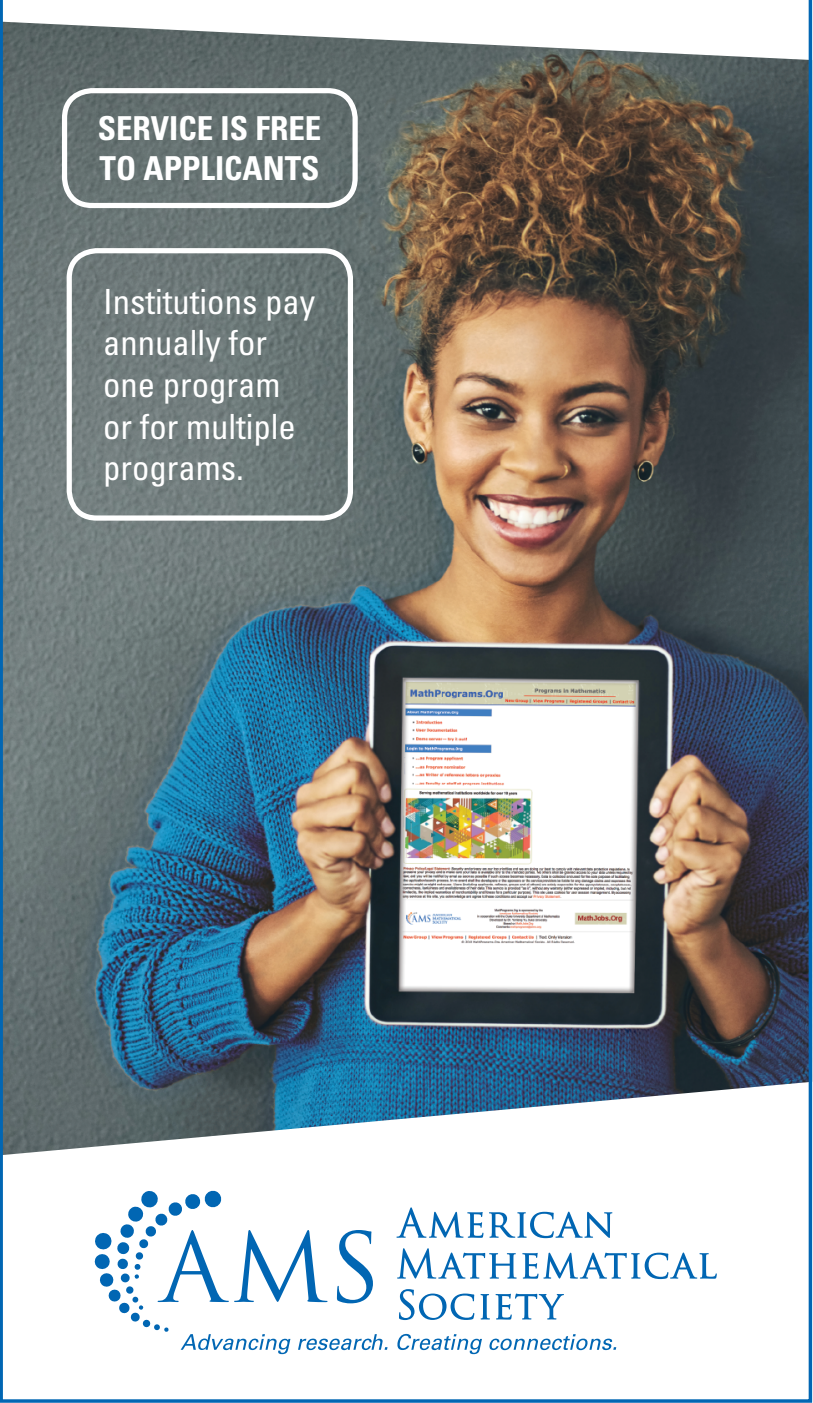

